\title{
Investigation of a New Version of the Liquid Embolic Agent PHIL with Extra-Low-Viscosity in an Endovascular Embolization Model
}

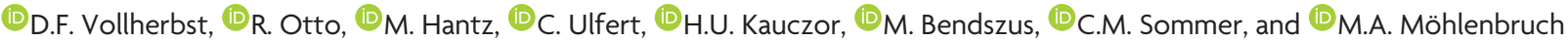

\begin{abstract}
BACKGROUND AND PURPOSE: The type and composition of an embolic agent have a relevant influence on the performance of endovascular embolization. The aim of this study was to investigate a new version of the liquid embolic agent precipitating hydrophobic injectable liquid (PHIL) with extra-low-viscosity in an in vivo embolization model.
\end{abstract}

MATERIALS AND METHODS: Twenty-four embolization procedures were performed in the porcine rete mirabile. Eight embolizations were performed with PHIL 25\% low viscosity, Squid 12, and standard PHIL 25\%, respectively. Procedure time, required volume of embolic agent, visibility of the embolic agent, embolization control, embolization extent (ie, penetration of the rete mirabile), amount of reflux, and degree of embolization distal to the rete mirabile were assessed.

RESULTS: All embolic agents were adequately visible. The embolization extent was not significantly different among the 3 investigated agents; however, there was a tendency toward a higher embolization extent for PHIL $25 \%$ low viscosity (median embolization extent: $88 \%$ [PHIL 25\% low viscosity]; 65\% [Squid 12]; 60\% [PHIL 25\%]; $P=.146$ ). The amount of reflux was significantly lower for the extra-low-viscosity agents PHIL 25\% low viscosity and Squid 12 compared with the standard PHIL 25\% (median reflux distance: 8 mm [PHIL 25\% low viscosity]; $6 \mathrm{~mm}$ [Squid 12]; $17 \mathrm{~mm}$ [PHIL 25\%]; $P=.011$ ). All other embolization features did not differ among agents.

CONCLUSIONS: PHIL 25\% low viscosity is a promising liquid embolic agent for endovascular embolization, featuring effective distal penetration, adequate visibility, a low amount of reflux, and good flow control.

ABBREVIATIONS: APA = ascending pharyngeal artery; HR-DVT = high-resolution digital volume tomography; LEA = liquid embolic agent; $L V=$ low viscosity; $\mathrm{RM}=$ rete mirabile

$E^{\prime}$ ndovascular embolization can be an effective treatment option for selected cerebral arteriovenous malformations and dural arteriovenous fistulas. ${ }^{1,2}$ Although the success rate of endovascular embolization of these vascular entities has improved in recent years, there is still an obvious need for further improvement, especially regarding the effectiveness and safety of the endovascular treatment of AVMs. ${ }^{3,4}$

The choice of the embolic agent has a relevant impact on the success of the endovascular therapy. ${ }^{4,5}$ For the endovascular treatment of AVMs and dural arteriovenous fistulas, liquid embolic agents (LEAs) are used most frequently. Different LEAs are cur-

Received March 28, 2018; accepted after revision June 12.

From the Department of Neuroradiology (D.F.V., R.O., M.H., C.U., M.B., M.A.M.) and Clinic for Diagnostic and Interventional Radiology (D.F.V., H.U.K., C.M.S.), Heidelberg University Hospital, Heidelberg, Germany; and Clinic for Diagnostic and Interventional Radiology (C.M.S.), Klinikum Stuttgart, Stuttgart, Germany.

Please address correspondence to Markus A. Möhlenbruch, MD, Department of Neuroradiology, University Hospital Heidelberg, INF 400, 69120 Heidelberg, Germany; e-mail: markus.moehlenbruch@med.uni-heidelberg.de

http://dx.doi.org/10.3174/ajnr.A5750 rently available that basically differ in the following aspects: mechanism of hardening (ie, polymerization or precipitation), adhesiveness, active component, medium inducing radiopacity, and viscosity. A recently introduced LEA with potential advantages over the established LEAs is the precipitation hydrophobic injectable liquid (PHIL; MicroVention, Tustin, California). PHIL is a precipitating, nonadhesive embolic agent that uses 2 specific copolymers (polylactide-co-glycolide and polyhydroxyethylmethacrylate) as active components and a covalently bound iodine component (triiodophenol) for radiopacity. The safety and efficacy of PHIL has been demonstrated in several clinical and experimental studies. ${ }^{6-10}$

The treatment of complex AVMs with large nidi or dural arteriovenous fistulas with large vascular networks can be impeded by incomplete penetration of the target lesion by the LEA, resulting in an occlusion of the feeding arteries but not of the arteriovenous shunt itself. ${ }^{11}$ LEAs with extra-low-viscosity could improve the success rate of these entities. ${ }^{12,13}$ Of the commercially available LEAs, the standard low-viscosity versions are Onyx 18 (Covidien, Irvine, California), Squid 18 (Emboflu, Gland, 
Switzerland), and PHIL 25\%. Currently, only Emboflu offers a commercially available extra-low-viscosity version (Squid 12).

The aim of this study was to investigate a new extra-low-viscosity version of the LEA PHIL in an in vivo endovascular embolization model. Squid 12 as a commercially available ethylene-vinyl alcohol copolymer-based extra-low-viscosity LEA and PHIL 25\% as a standard low-viscosity LEA were used as control agents.

\section{MATERIALS AND METHODS}

\section{Endovascular Embolization Model}

The porcine rete mirabile (RM) is an established embolization model for the investigation of embolic agents and embolization techniques. ${ }^{10,14-16}$ The RM is a reticular network of blood vessels, located bilaterally at the base of the skull in pigs with a connection through the midline. It is mainly supplied by the ascending pharyngeal artery (APA), a branch of the common carotid artery.

\section{Animal Procedure}

State Animal Care and Ethics Committee approval was obtained. All experiments were performed in accordance with the Guide for the Care and Use of Laboratory Animals.

Healthy female pigs (German Landrace) with a body weight of 35-45 kg were used. Anesthesia was introduced with an intramuscular injection of azaperone $(6 \mathrm{mg} / \mathrm{kg}$; Stresnil; Janssen Animal Health, Beerse, Belgium), midazolam (0.4 mg/kg; Dormicum; Roche, Basel, Switzerland), and ketamine (10 mg/kg; Ketamin; Medistar, Hannover, Germany). For maintenance, intravenous injections of midazolam and ketamine were performed with a syringe driver, dosed according to the effect. Intubation was performed for airway management. After surgical cut-down, a $6 \mathrm{~F}$ introducer sheath was inserted into the right femoral artery. The animals were sacrificed 2 hours after embolization with an intravenous injection of $20 \mathrm{~mL}$ of potassium chloride $7.5 \%$. The RMs were explanted according to the technique described by Eliyas et al. ${ }^{17}$ Subsequently, the RM were transferred to $4 \%$ buffered paraformaldehyde and embedded in paraffin.

\section{Embolization Technique}

A 5F guiding catheter (Radifocus Glidecath Vertebral; Terumo Europe, Leuven, Belgium) was positioned in the common carotid artery, proximal to the origin of the APA under fluoroscopic guidance (Artis zee; Siemens, Erlangen, Germany). Subsequently, a diagnostic angiography of the respective side of the RM was performed via the guiding catheter. Afterward, a $1.3 \mathrm{~F}$ microcatheter (Headway Duo; MicroVention), which was used with a $0.014-$ inch guidewire (Traxcess 14; MicroVention), was inserted through the guiding catheter and positioned in the base of the RM. After superselective angiography via the microcatheter for confirmation of the correct catheter position, the microcatheter was flushed with $1 \mathrm{~mL}$ of dimethyl-sulfoxide. A syringe-catheter interface adapter was connected to the microcatheter. Subsequently, embolization of the RM was performed by manual and pulsatile injection of the respective LEA. Per injection, a certain amount of reflux was tolerated, defined as a distance of $5 \mathrm{~mm}$ of the APA. In the case of reflux exceeding this limit or in the case of embolization of the efferent vessels of the RM, the injection was stopped and the procedure was paused for 60 seconds. At every pause and at the end of every procedure, an x-ray of the RM was performed for assessment of the intra- and postprocedural embolization extent. The procedure was terminated if the respective RM was completely embolized. The procedure was terminated prematurely in the following scenarios: 1) complete embolization of the APA with imminent embolization of the common carotid artery, 2) distal embolization with imminent embolization of the brain, or 3) embolization of the contralateral RM. One minute after termination of the embolization procedure, the microcatheter was removed under fluoroscopy while monitoring the LEA cast for stability. All interventions were performed by 2 interventionalists (D.F.V. and M.A.M. with 5 and 12 years of experience in endovascular interventions, respectively).

\section{PHIL 25\% Low Viscosity}

The chemical composition and the polymer backbone of PHIL $25 \%$ low viscosity (LV) are equivalent to those in the currently available versions of PHIL. The concentration of PHIL 25\% LV is identical to that of the standard PHIL 25\% (the numbers indicate the concentration in weight per weight). The difference between the extra-low-viscosity and the standard version of PHIL 25\% is the length of the polymer chains. The polymer chains are shorter for PHIL 25\% LV, resulting in a lower molecular weight of the single copolymer molecules. The lower molecular weight leads to the lower viscosity of PHIL 25\% LV.

\section{Study Groups}

In total, 24 embolization procedures were performed. We defined 3 study groups: PHIL 25\% LV, Squid 12, and standard PHIL 25\%, with 8 embolization procedures per study group, respectively.

\section{Study Goals}

The aim of each embolization procedure was complete embolization of the respective side of the RM.

The total procedure time and the used volume of LEA per procedure (including the dead space of the microcatheter of 0.35 $\mathrm{mL}$ ) were recorded. The ease of visualization in fluoroscopy and in $\mathrm{x}$-ray was graded on a 3 -point scale (1, definitely not visible; 2 , probably visible; 3 , definitely visible). The ability to stop forward flow when the injection stops was graded on a 5-point scale (1, uncontrolled high forward flow; 2, partially controlled high forward flow; 3 , partially controlled moderate forward flow; 4 , controlled low forward flow; 5 , no forward flow). The degree of distal embolization was assessed by counting the number of events of embolization distal to the RM per procedure.

For the analysis of the embolization extent, the area of the respective side of the $\mathrm{RM}$ was determined in the preinterventional posteroanterior angiogram using the syngo Acquisition Workplace (Siemens) by delineating the perimeter of the RM (Fig 1A). The area of the embolized portion of the RM was delineated in the same fashion in the postinterventional x-ray (Fig $1 F$ ). The ratio of these 2 areas (preinterventional angiogram and postinterventional $\mathrm{x}$-ray) was calculated and defined as the embolization extent, as described previously. ${ }^{10,15}$

For evaluation of the 3D distribution of the LEA in the RM, a high-resolution digital volume tomography (HR-DVT, 3D Accuitomo 170; J. Morita, Tokyo, Japan; FOV $=40 \times 40 \mathrm{~mm}$, volt- 


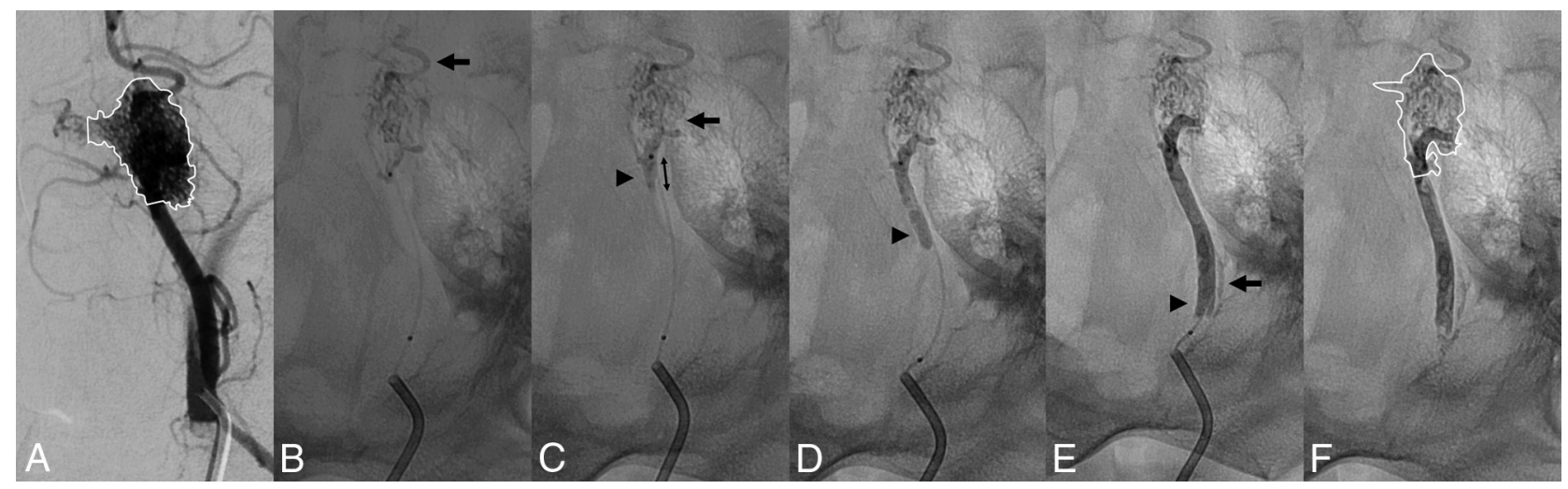

FIG 1. Representative embolization procedure with PHIL $25 \% \mathrm{LV}$. A, Before the embolization procedure, a diagnostic angiography is performed through a guiding catheter. The RM is delineated in the diagnostic angiography image with complete filling of the RM. $B, X$-ray after the first injection. After the first injection, most of the RM is already embolized. The injection is stopped because of embolization distal to the RM (arrow). C, X-ray after the second injection. The second injection leads to slight additional filling of the lateral parts of the RM (black arrow). The injection is stopped because of reflux (arrowhead). Retrospectively, this is the injection with which the maximal embolization extent was reached. Accordingly, the reflux distance is measured in this image (double arrow). X-rays after the fifth $(D)$ and eighth $(E)$ injections. No more filling of the RM is achieved with the following injections, which were all stopped because of reflux (arrowheads). After the eighth injection, the procedure is terminated because of reflux of the LEA into the APA (arrow). F, After termination of the procedure, the catheters are removed and the embolized portion of the RM is delineated. The area of the completely filled RM $(A)$ and the area of the embolized RM $(F)$ are related, resulting in the embolization extent.

\section{Summary of the results ${ }^{\mathrm{a}}$}

\begin{tabular}{|c|c|c|c|c|}
\hline & PHIL 25\% LV & Squid 12 & Standard PHIL 25\% & $P$ Value \\
\hline Total procedure time $(\mathrm{s})$ & $395(310-528)$ & $436(430-501)$ & $328(239-479)$ & $.386^{\mathrm{b}}$ \\
\hline Required volume of embolic agent $(\mathrm{mL})$ & $0.7(0.7-0.9)$ & $0.8(0.7-0.9)$ & $0.7(0.6-0.7)$ & $.121^{\mathrm{b}}$ \\
\hline Visibility & $3(3-3)$ & $3(3-3)$ & $3(3-3)$ & NA \\
\hline Forward flow control & $5(5-5)$ & $5(5-5)$ & $5(5-5)$ & $.335^{\mathrm{b}}$ \\
\hline Embolization extent (\%) & $87.7(68.0-100)$ & $64.6(52.2-73.0)$ & $60.4(27.0-75.9)$ & $.146^{\mathrm{b}}$ \\
\hline Reflux distance (mm) & $8(6-8)$ & $6(5-10)$ & $17(14-21)$ & $\begin{array}{c}.011^{\mathrm{b}} \\
>.999^{\mathrm{c}} \\
.049^{\mathrm{d}} \\
.017^{\mathrm{e}}\end{array}$ \\
\hline $\begin{array}{l}\text { Events of embolization distal to the RM } \\
\text { per procedure (No.) }\end{array}$ & $0(0-1)$ & $0(0-0)$ & $0(0-0)$ & $.527^{\mathrm{b}}$ \\
\hline
\end{tabular}

Note:-NA indicates that the $P$ value was not available because all values are identical.

${ }^{a}$ Data are presented as median (lower quartile-upper quartile).

${ }^{\mathrm{b}}$ Kruskal-Wallis test.

c Post hoc Dunn test, PHIL 25\% LV vs Squid 12.

d Post hoc Dunn test, PHIL 25\% LV vs standard PHIL 25\%.

e Post hoc Dunn test, Squid 12 vs. standard PHIL 25\%.

age $=90 \mathrm{kV}$, amperage $=8.0 \mathrm{~mA}$, rotation $=360^{\circ}$, reconstruction with isotropic voxels with a slice thickness of $80 \mu \mathrm{m}$ ) of the explanted, paraffin-embedded RM was performed. The 3D distribution of the LEA was described qualitatively. An analysis of the embolization extent using the HR-DVT datasets was consciously not performed for 2 reasons: 1 ) preparation artifacts that occurred in a few specimens during the dissection of the RM, and 2) the nonembolized portions of the RM that could not be examined in HR-DVT due to the limited soft-tissue contrast in this technique.

To assess the amount of reflux, we measured the reflux distance, defined as the distance of LEA in the APA, on reaching the maximal embolization extent (Fig 1C). The reflux distance at the end of the procedure was consciously not used because for most the procedures, the APA was finally embolized completely or near-completely because of repeat reflux.

\section{Statistics}

GraphPad Prism software (Version 7.02; GraphPad Software, San Diego, California) was used for data analysis. Quantitative data are presented as medians (lower quartile-upper quartile). To evaluate statistical differences among the study groups, we performed the Kruskal-Wallis test with a post hoc Dunn test with a $P$ value of .05 as the threshold for statistical significance.

\section{RESULTS}

All procedures were performed as planned. No event of technical failure, such as catheter occlusion or catheter entrapment, or indirect angiographic signs of vasotoxicity, such as embolizationinduced vasospasm, were observed.

The results are summarized in the Table. A representative embolization procedure is shown in Fig 1.

All embolic agents were definitely visible on fluoroscopy and in x-ray (Fig 2). We observed a slightly better visibility for standard PHIL 25\% compared with PHIL 25\% LV and Squid 12.

The embolization extent (illustrated in Fig $3 A$ ) was not significantly different for the 3 study groups; however, there was a trend toward a higher embolization extent for PHIL 25\% LV (medians: 


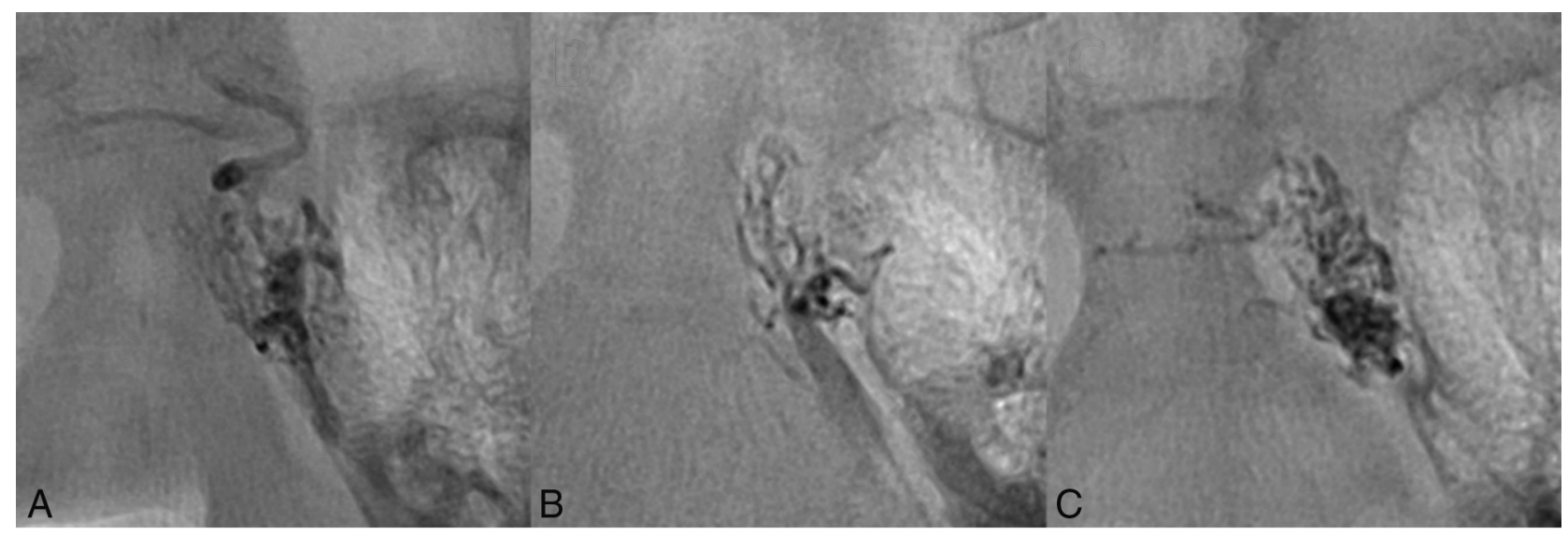

FIG 2. Visibility of the embolic agents. X-rays after the first injection shown for PHIL $25 \%$ LV (A), Squid 12 (B), and standard PHIL $25 \%$ (C). Note the adequate visibility of all 3 embolic agents.
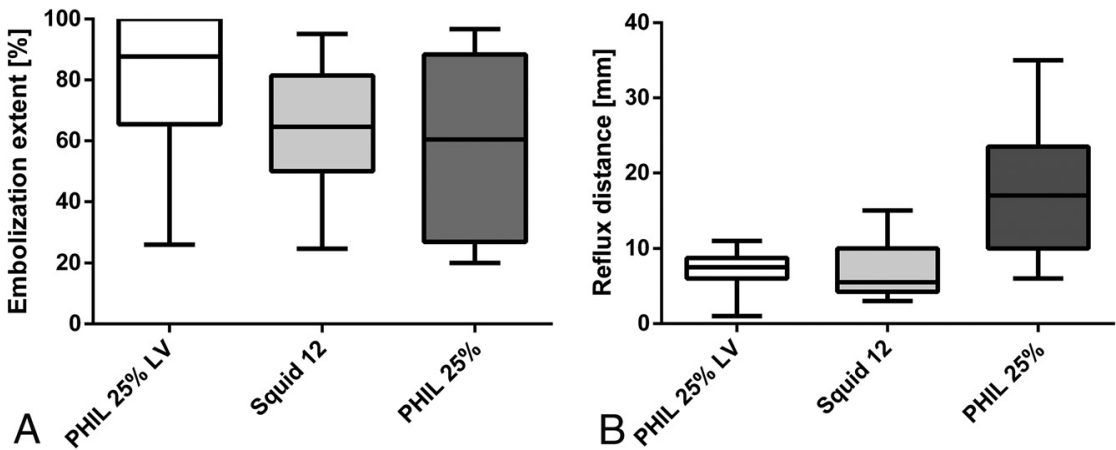

FIG 3. Illustration of embolization extent and reflux distance. $A$, The embolization extent tended to be higher for PHIL $25 \% \mathrm{LV}$, however, without reaching statistical significance. $B$, The reflux distance was significantly lower for the 2 extra-low-viscosity LEAs PHIL 25\% LV and Squid 12 compared with standard PHIL $25 \%$.

$87.7 \%, 64.6 \%$, and $60.4 \%$, respectively). For PHIL 25\% LV and for Squid 12, but not for standard PHIL 25\%, the first 3 injections were assessed as the most effective. These effective injections were not accompanied by reflux or were accompanied by only low amounts of reflux. After these effective injections, in most of the embolization procedures, there was repeat reflux until complete or near-complete filling of the APA with subsequent termination of the procedure.

The 3D distribution of the LEAs in HR-DVT showed a good correlation qualitatively to the $2 \mathrm{D}$ distribution of the LEAs in $\mathrm{x}$-ray (Fig 4). There were no substantial differences for the 3 LEAs regarding their $3 \mathrm{D}$ distribution. For procedures with complete or near-complete filling, there was homogeneous enhancement of the RM, whereas for procedures with low-embolization extents, various filling defects were identified.

The reflux distance (illustrated in Fig $3 B$ ) was lower for PHIL 25\% LV and Squid 12 compared with standard PHIL 25\% (medians: 8,6 , and $17 \mathrm{~mm}$, respectively; $P=.011$ ), however, with no difference between the extra-low-viscosity LEAs PHIL 25\% LV and Squid 12.

For PHIL 25\% LV and Squid for 12, there was 1 case of controlled low forward flow for each of them. For the remaining 7 procedures of these study groups and for all procedures of standard PHIL 25\%, there was excellent flow control with no event of unwanted forward flow. The total number of events of emboliza- tion distal to the RM was $n=3$ for PHIL $25 \% \mathrm{LV} ; n=2$ for Squid 12; and $n=2$ for standard PHIL 25\% without significant differences.

The total procedural time and the volume of embolic agent used were also not significantly different among the 3 study groups.

\section{DISCUSSION}

In this experimental study, the new extra-low-viscosity LEA PHIL 25\% LV was investigated in an acute in vivo embolization model. The embolization extent tended to be higher for PHIL 25\% LV compared with Squid 12 and standard PHIL 25\%, while both extra-low-viscosity LEAs (PHIL 25\% LV and Squid 12) featured a significantly lower amount of reflux compared with standard PHIL 25\%. All investigated embolic agents showed good flow control.

Several different concentrations are available for each of the currently commercially available precipitating, nonadhesive LEAs: a low-viscosity version (Onyx 18, Squid 18, and PHIL 25\%), a medium-viscosity version (Onyx 20 and PHIL 30\%), and a high-viscosity version (Onyx 34 and PHIL 35\%). For the lowviscosity versions Onyx 18 and PHIL 25\%, it was shown in the experimental setting that embolization characteristics and embolization extent are similar. ${ }^{9,10}$ Also Squid 18 seems to show embolization features that are like those in the equally viscous Onyx $18 .^{13}$ As initially indicated, of the commercially available precipitating, nonadhesive LEAs, Squid 12 is the only extra-low-viscosity version so far.

Intra- and postprocedural visibility in the angiography suite is a crucial requirement for the LEA being used. ${ }^{18,19}$ Adequate visibility enables real-time embolization control and assessment of the current status of embolization (embolized and nonembolized portions of a lesion). ${ }^{18,19} \mathrm{~A}$ decrease in viscosity could theoretically lead to a decrease in visibility. In this study, all investigated LEAs were definitely visible on fluoroscopy and $\mathrm{x}$-ray. However, a slightly better visibility was noted for standard PHIL 25\% compared with the extra-low-viscosity 


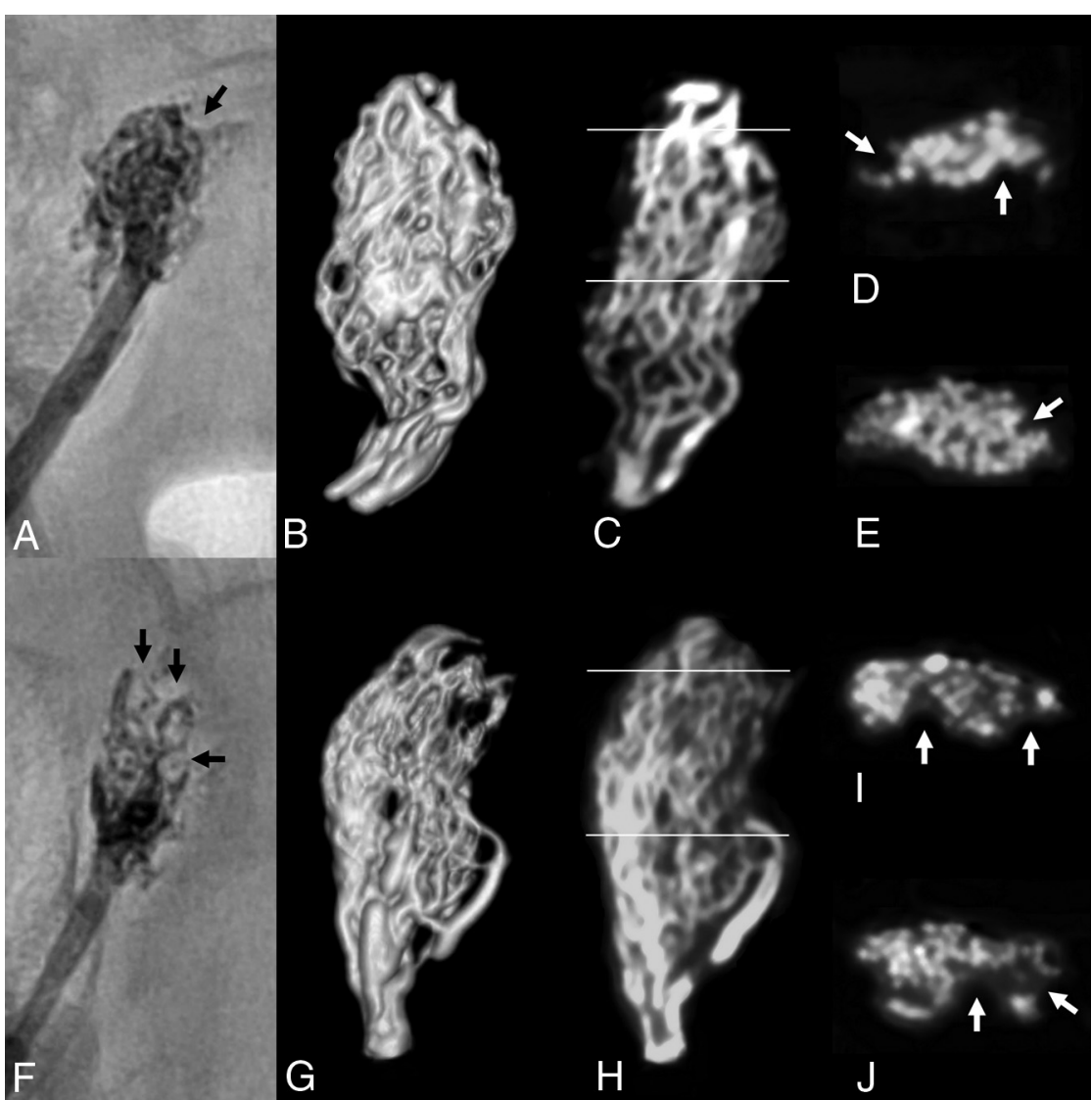

FIG 4. Distribution of the LEA in HR-DVT. The distribution of the LEA in HR-DVT is shown for 2 representative cases. A-E, PHIL 25\% LV. F-J, Standard PHIL 25\%. A and F, Postinterventional x-rays. $B$ and $G$, Volume-rendering of the HR-DVT dataset. $C$ and H, Coronal HR-DVT images. D, E, I, and $J$, Axial HR-DVT images of the middle ( $E$ and $/$ ) and the distal ( $D$ and $/$ ) parts of the RM (lines in $C$ and $H$ indicate the position of the axial planes). Note the perceptibility of single blood vessels of the RM in the high-resolution HR-DVT images. Well-circumscribed filling defects were identified in the axial HR-DVT images, which were particularly detected in the distal, only partially embolized parts of the RM (white arrows). The same filling defects were also seen in the 2D x-rays (black arrows).

LEAs PHIL 25\% LV and Squid 12. Considering that the porcine $\mathrm{RM}$ is a rather simple vascular structure with a homogeneous organization, in complex vascular pathologies with embolized and nonembolized blood vessels of different sizes overlapping each other, the visibility of these LEAs could be different.

In this study, the embolization extent was highest for PHIL 25\% LV, followed by Squid 12 and standard PHIL 25\%, however, without reaching statistical significance. Nevertheless, these results indicate that for selected vascular entities, extra-low-viscosity LEAs may be advantageous over the currently available standard low-viscosity LEAs (Onyx 18, Squid 18, and PHIL 25\%). Naturally, the requirements for the respective LEA in terms of the adequate viscosity differ for different lesions with regard to type (eg, AVMs or dural arteriovenous fistulas), flow (eg, high-flow or low-flow), extent (eg, small or large lesions), and configuration of the vessels of the lesion (eg, large vessels, small vessels, or aneurysms). ${ }^{20,21}$ For Squid 12, previous studies in the literature have already noted that penetration of the nidus may be more effective than with standard low-viscosity embolic agents, such as Squid 18 or Onyx $18 .^{13,22,23}$

Several advantages of PHIL over cyanoacrylates and ethylenevinyl alcohol-based LEAs are discussed in the literature, includ- ing its ease of use, fast plug formation, consistent visibility, low artifacts on postinterventional CT, lower required volumes of LEA, and the lack of intraoperative hazards. ${ }^{6,9,24,25}$ Given these potential advantages of the currently available versions of PHIL and the results of the present study, PHIL 25\% LV appears to be an effective agent for endovascular embolization of selected pathologies.

We could show that the degree of reflux is significantly lower for the extralow-viscosity LEAs PHIL 25\% LV and Squid 12 compared with the standard PHIL 25\%. This aspect can be highly relevant in clinical practice. Reflux carries the risk of closing the feeding artery prematurely and increases the probability of catheter entrapment; and especially in AVMs or dural arteriovenous fistulas with short feeding arteries, reflux increases the risk of unwanted embolization of arteries supplying healthy tissue, eventually leading to infarction. ${ }^{18,26}$

In this study, for PHIL 25\% LV and Squid 12, embolization was most effective with approximately the first 3 injections. Afterward, in most of the cases, reflux occurred and no more penetration of the RM, especially of the distal parts, was possible. Accordingly, there was actually no plug formation with consecutive effective embolization for the 2 extra-low-viscosity LEAs. This concern can potentially be solved using a dual-lumen micro-balloon catheter for prevention of reflux. ${ }^{27,28}$ Another option is to use small amounts of the more viscous versions of these LEAs for plug formation with subsequent filling of the lesion with extra-lowviscosity LEAs in a manner similar to the pressure cooker technique. ${ }^{29}$ This approach was already described in the literature with respect to Squid, using Squid 18 for the initial plug formation followed by embolization with Squid $12 .{ }^{13}$

A conceivable drawback of extra-low-viscosity LEAs is poor flow control and early distal embolization, which risks premature closing of the draining veins, potentially leading to intra- or postprocedural hemorrhage, or embolization of healthy tissue distal to the lesion to be treated, potentially leading to stroke. ${ }^{27,30}$ In this experimental study, flow control was good and the frequency of embolization distal to the RM was low for all 3 LEAs. However, in clinical practice, due to the more complex angioarchitecture and different flow patterns of AVMs and dural arteriovenous fistulas, flow characteristics could be different and the risk of distal embolization could be higher for extra-low-viscosity LEAs, especially for lesions with high-flow shunts. Therefore, especially the first injections should be of low volume and with a high extent of 
caution concerning unwanted forward flow exceeding the distal parts of the treated lesion.

This study has limitations. First, PHIL 25\% LV was only compared with 2 other LEAs. Comparison with other LEAs, such as Onyx 18, could have identified more characteristics and differences between PHIL 25\% LV and the currently available embolic agents. However, as mentioned above, recent experimental studies showed that the embolization features of Onyx 18 and standard PHIL 25\% are similar., ${ }^{9,10}$ Accordingly, to reduce the number of required laboratory animals, the above-mentioned study groups were defined. Second, the number of experiments was relatively small; however, the findings were consistent in the different study groups. Third, the survival time after embolization was short, precluding a meaningful analysis on the biocompatibility of the LEAs. Fourth, the transferability of experimental models to clinical practice is generally limited. Fifth, the creation of an arteriovenous fistula would have made the embolization model more like an AVM. Sixth, the analysis of the embolization extent that was used in this study does not take into account central filling defects or the density of the LEA inside the RM.

\section{CONCLUSIONS}

PHIL 25\% LV is a promising LEA for endovascular embolization, featuring effective distal penetration, adequate visibility, a low amount of reflux, and good flow control.

Disclosures: Dominik F. Vollherbst-UNRELATED: Travel/Accommodations/Meeting Expenses Unrelated to Activities Listed: MicroVention and Stryker, Comments: Travel support*; OTHER RELATIONSHIPS: This study was technically supported by MicroVention. Christian Ulfert-UNRELATED: Travel/Accommodations/Meeting Expenses Unrelated to Activities Listed: MicroVention, Stryker*. Hans U. KauczorUNRELATED: Payment for Lectures Including Service on Speakers Bureaus: Siemens, Boehringer Ingelheim, Philips Healthcare, Bracco. Martin Bendszus-UNRELATED: Board Membership: Data and Safety Monitoring Board for Vascular Dynamics, Guerbet, Boehringer Ingelheim; Consultancy: Codman Neurovascular, Roche, Guerbet, Boehringer Ingelheim, Braun; Grants/Grants Pending: German Research Foundation Hopp Foundation, Novartis, Siemens, Guerbet, Stryker, Covidien, European Union*; Payment for Lectures Including Service on Speakers Bureaus: Novartis, Roche, Guerbet, Teva Pharmaceutical Industries, Bayer AG, Codman Neurovascular. Markus A. Möhlenbruch—UNRELATED: Board Membership: Codman Neurovascular; Consultancy: MicroVention, Medtronic, Stryker; Grants/Grants Pending: Balt, MicroVention*; Payment for Lectures Including Service on Speakers Bureaus: MicroVention, Medtronic, Stryker. ${ }^{\star}$ Money paid to the institution.

\section{REFERENCES}

1. Pierot L, Cognard C, Herbreteau D, et al. Endovascular treatment of brain arteriovenous malformations using a liquid embolic agent: results of a prospective, multicentre study (BRAVO). Eur Radiol 2013;23:2838-45 CrossRef Medline

2. Gross BA, Albuquerque FC, Moon K, et al. Evolution of treatment and a detailed analysis of occlusion, recurrence, and clinical outcomes in an endovascular library of $\mathbf{2 6 0}$ dural arteriovenous fistulas. J Neurosurg 2017;126:1884-93 CrossRef Medline

3. Singfer U, Hemelsoet D, Vanlangenhove P, et al. Unruptured brain arteriovenous malformations: primary ONYX embolization in ARUBA (A Randomized Trial of Unruptured Brain Arteriovenous Malformations)-eligible patients. Stroke 2017;48:3393-96 CrossRef Medline

4. van Rooij WJ, Jacobs S, Sluzewski M, et al. Curative embolization of brain arteriovenous malformations with Onyx: patient selection, embolization technique, and results. AJNR Am J Neuroradiol 2012; 33:1299-304 CrossRef Medline

5. Gross BA, Du R. Diagnosis and treatment of vascular malforma- tions of the brain. Curr Treat Options Neurol 2014;16:279 CrossRef Medline

6. Varadharajan S, Ramalingaiah AH, Saini J, et al. Precipitating hydrophobic injectable liquid embolization of intracranial vascular shunts: initial experience and technical note. J Neurosurg 2017 Dec 1:1-6. [Epub ahead of print] CrossRef Medline

7. Lamin S, Chew HS, Chavda S, et al. Embolization of intracranial dural arteriovenous fistulas using PHIL liquid embolic agent in $\mathbf{2 6}$ patients: a multicenter study. AJNR Am J Neuroradiol 2017;38: 127-31 CrossRef Medline

8. Samaniego EA, Kalousek V, Abdo G, et al. Preliminary experience with Precipitating Hydrophobic Injectable Liquid (PHIL) in treating cerebral AVMs. J Neurointerv Surg 2016 Jan 27. [Epub ahead of print] CrossRef Medline

9. Vollherbst DF, Sommer CM, Ulfert C, et al. Liquid embolic agents for endovascular embolization: evaluation of an established (Onyx) and a novel (PHIL) embolic agent in an in vitro AVM model. AJNR Am J Neuroradiol 2017;38:1377-82 CrossRef Medline

10. Vollherbst DF, Otto R, von Deimling A, et al. Evaluation of a novel liquid embolic agent (precipitating hydrophobic injectable liquid (PHIL)) in an animal endovascular embolization model. J Neurointerv Surg 2018;10:268-74 CrossRef Medline

11. Saatci I, Geyik S, Yavuz K, et al. Endovascular treatment of brain arteriovenous malformations with prolonged intranidal Onyx injection technique: long-term results in 350 consecutive patients with completed endovascular treatment course. J Neurosurg 2011; 115:78-88 CrossRef Medline

12. van Rooij WJ, Sluzewski M, Beute GN. Brain AVM embolization with Onyx. AJNR Am J Neuroradiol 2007;28:172-77; discussion 178 Medline

13. Akmangit I, Daglioglu E, Kaya T, et al. Preliminary experience with Squid: a new liquid embolizing agent for AVM, AV fistulas and tumors. Turk Neurosurg 2014;24:565-70 CrossRef Medline

14. Massoud TF, Ji C, Viñuela F, et al. An experimental arteriovenous malformation model in swine: anatomic basis and construction technique. AJNR Am J Neuroradiol 1994;15:1537-45 Medline

15. Haussen DC, Ashour R, Johnson JN, et al. Direct continuous measurement of draining vein pressure during Onyx embolization in a swine arteriovenous malformation model. J Neurointerv Surg 2015; 7:62-66 CrossRef Medline

16. Gentric JC, Raymond J, Batista A, et al. Dual-lumen balloon catheters may improve liquid embolization of vascular malformations: an experimental study in swine. AJNR Am J Neuroradiol 2015;36: 977-81 CrossRef Medline

17. Eliyas JK, Niekrasz M, Wardrip C, et al. Focused post mortem dissection technique for harvest of rete mirabile in domestic swine (Sus scrofa). J Neurointerv Surg 2016;8:973-76 CrossRef Medline

18. Weber W, Kis B, Siekmann R, et al. Endovascular treatment of intracranial arteriovenous malformations with Onyx: technical aspects. AJNR Am J Neuroradiol 2007;28:371-77 Medline

19. Duran R, Sharma K, Dreher MR, et al. A novel inherently radiopaque bead for transarterial embolization to treat liver cancer: a pre-clinical study. Theranostics 2016;6:28-39 CrossRef Medline

20. Ayad M, Eskioglu E, Mericle RA. Onyx: a unique neuroembolic agent. Expert Rev Med Devices 2006;3:705-15 CrossRef Medline

21. Diaz O, Scranton R. Endovascular treatment of arteriovenous malformations. Handb Clin Neurol 2016;136:1311-17 CrossRef Medline

22. Szatmáry Z, Hillman J, Finitsis S. Meningioma embolization with the pressure cooker technique using Squid 12. Interv Neuroradiol 2017;23:441-43 CrossRef Medline

23. Erbahceci Salik A, Islim F, Akgul A, et al. Concomitant transarterial and transvenous embolization of a pelvic arteriovenous malformation using a new liquid embolic agent, Squid-12 and detachable coils. Case Rep Vasc Med 2014;2014:972870 CrossRef Medline

24. Koçer N, Hanımoğlu H, Batur Ş, et al. Preliminary experience with precipitating hydrophobic injectable liquid in brain arteriovenous malformations. Diagn Interv Radiol 2016;22:184-89 CrossRef Medline 
25. Leyon JJ, Chavda S, Thomas A, et al. Preliminary experience with the liquid embolic material agent PHIL (Precipitating Hydrophobic Injectable Liquid) in treating cranial and spinal dural arteriovenous fistulas: technical note. J Neurointerv Surg 2016;8:596-602 CrossRef Medline

26. Jagadeesan BD, Grigoryan M, Hassan AE, et al. Endovascular balloonassisted embolization of intracranial and cervical arteriovenous malformations using dual-lumen coaxial balloon microcatheters and Onyx: initial experience. Neurosurgery 2013;73(2 Suppl Operative): ons238-43; discussion ons243 CrossRef Medline

27. Shi ZS, Loh Y, Gonzalez N, et al. Flow control techniques for Onyx embolization of intracranial dural arteriovenous fistulae. J Neurointerv Surg 2013;5:311-16 CrossRef Medline
28. Vollherbst DF, Otto R, Do TD, et al. Extra-small dual-lumen microballoon catheters can improve endovascular embolization: an experimental in vivo and in vitro study. J Neurointerv Surg 2018 Mar 19. [Epub ahead of print] CrossRef Medline

29. Chapot R, Stracke P, Velasco A, et al. The pressure cooker technique for the treatment of brain AVMs. J Neuroradiol 2014;41: 87-91 CrossRef Medline

30. Abud DG, Riva R, Nakiri GS, et al. Treatment of brain arteriovenous malformations by double arterial catheterization with simultaneous injection of Onyx: retrospective series of 17 patients. AJNR Am J Neuroradiol 2011;32:152-58 CrossRef Medline 